Section: Regenerative Medicine and Biomaterials

\title{
Muscle-derived precursor cells isolated on the basis of differential adhesion properties respond
} differently to capillary flow

Minal Patel, Hayley Mulhall, Khalid Al-Quatani, Mark Lewis, Ivan Wall

M. Patel - Regenerative Medicine Bioprocessing Unit, Department of Biochemical Engineering, University

College London, Torrington Place, London WC1E 7JE; minal.patel@ucl.ac.uk

H. Mulhall - Centre for Biomedical Engineering, Faculty of Engineering and Physical Sciences (J5), University of Surrey, Guildford GU2 7XH; H.Mulhall@Surrey.ac.uk

K. Al-Quatani, M. Lewis - Muscle Cellular and Molecular Physiology Group, Institute of Sport and Physical Activity Research and UCL Eastman Dental Institute, Polhill Avenue, Bedford MK41 9EA; k.alqahtani@eastman.ucl.ac.uk; Mark.Lewis@beds.ac.uk I. Wall - Regenerative Medicine Bioprocessing Unit, Department of Biochemical Engineering, University College London, Torrington Place, London WC1E 7JE \& Department of Nanobiomedical Science and WCU Research Centre, Dankook University, Cheonan, 330-714, South Korea; i.wall@ucl.ac.uk

*Corresponding author: Dr Ivan Wall, Tel: +44 (0)20 76793918 Fax: +44 (0)20 72090703 Email: i.wall@ucl.ac.uk 


\begin{abstract}
Capillary shear stress can improve osteogenic differentiation in muscle-derived precursor cells (MDPCs). This has implications for large-scale bioprocessing of cell therapies where capillary transfer is needed. The recovery, viability and osteogenic differentiation potential of two subsets of MDPCs, early-adherent pre-plate 1 (PP1) and late-adherent PP3 populations, have been examined: PP1 MDPCs produced a greater degree of osteogenic differentiation than PP3 MDPCs, quantified by Alizarin Red S staining intensity $(\mathrm{p}<0.05)$. For both cell populations, capillary flow induced significant increases in Alizarin Red S staining $(\mathrm{p}<0.05)$. However, PP1 cells were more susceptible to capillary flow-induced damage than PP3 cells and this was dependent on duration of exposure. Overall, results indicate that different cell subsets, even from within a single tissue, can respond variably to capillary shear stress, necessitating its precise monitoring and control.
\end{abstract}

Keywords: differential adhesion, muscle-derived precursor cells, osteogenic differentiation, shear stress, stem cells

\title{
Mathematical annotation
}

$\tau \approx 32 Q \mu / \pi d^{3}$

$\tau=$ average capillary wall shear stress in the capillary

$Q=$ fluid flow rate

$d=$ capillary diameter

$\mu=$ suspension viscosity 


\section{Introduction}

Capillary wall shear stress, such as that encountered during bioprocessing of regenerative cell populations, can contribute to osteogenic differentiation in muscle-derived precursor cells (Mulhall et al. 2010). If osteoid cell material is not the desired differentiation product of the process, then shear stresses encountered in the bioprocessing environment during capillary transfer of cell suspensions need to be carefully regulated and their effects defined, to ensure purity of the cell product is not compromised.

It is widely recognized that bone marrow-derived stromal cells and adipose-derived precursors undergo enhanced osteogenic differentiation in response to laminar flow and for adhered cells, $0.23-1.2 \mathrm{~N} \mathrm{~m}^{-2}$ of laminar flow-induced shear can promote this (Grellier et al. 2009; Knippenberg et al. 2005; Kreke et al. 2008). The particular method by which laminar flow is applied can also influence osteogenic responses in cells. In this paper, we have adopted a different approach, instead applying capillary shear forces representative of events such as trypsinization and suspension of these adherent cells that is necessary for the 'whole bioprocess' of automated cell expansion and differentiation (Zoro et al. 2009).

Cell populations isolated from adult human tissues are extremely heterogeneous, due to factors such as stochastic variation in biological age of individual cells, differential responses to environmental stimuli etc. Isolating cells on the basis of differential adhesion properties can reduce this heterogeneity, as progenitor cells in culture will adhere rapidly when plated due to intrinsic elevated integrin activation, whereas mature cell subsets will require longer periods of time to adhere (Davies et al. 2010; Jones and Watt 1993; Dowthwaite et al. 2004). In muscle, it has been reported that early adherent cells have progenitor properties whereas late adherent cells have a more mature myogenic phenotype and slow growth properties (Lee et al. 2000; Sinanan et al. 2006).

In this paper, we exposed both early-adherent preplate (PP) -1 and late-adherent (PP3) subsets of MDPCs to laminar flow through a narrow-gauge capillary to determine whether distinct profiles in immediate recovery, viability in culture and osteogenic differentiation potential were evident in the two populations.

\section{Materials and methods}

\section{Muscle-derived stem cells}


MDPCs were obtained from masseter muscle of p5 male Royal College of Surgeons rats following enzymic digestion of tissue, as previously described (Rando and Blau 1994). The cell suspension was serially plated into three different plates, pre-plate 1, 2 and 3 (PP1, PP2, and PP3 respectively), based on their adhesion properties following a previously described method (Lee et al. 2000). After $1 \mathrm{~h}$ of initial plating, non-adherent cells in suspension were removed and transferred to a new flask for a period of $48 \mathrm{~h}$. Fresh GM was added to the $1^{\text {st }}$ set of adherent cells (PP1). The non-adherent cells in suspension from the $2^{\text {nd }}$ flask (PP2) (after the 48 h) were transferred to a new flask for about 5-7 days (PP3). Cells were cultured in growth medium (DMEM $+10 \% \mathrm{v} / \mathrm{v}$ foetal calf serum $+1 \%$ antibiotic/antimycotic solution; all from Invitrogen) and cultured at $37^{\circ} \mathrm{C}$ and $5 \% \mathrm{CO}_{2}$. Cells were used for experiments within the first 2 passages.

\section{Induction of capillary shear stress}

Cells $\left(3 \times 10^{5}\right.$ cells $\left./ \mathrm{ml}\right)$ were loaded into a $20 \mathrm{ml}$ syringe barrel connected to an opposing $20 \mathrm{ml}$ syringe by a small diameter capillary of $0.318 \mathrm{~mm}$ (24 gauge) x $10 \mathrm{~mm}$, in 316 stainless steel (Cooper's Needleworks, Birmingham, UK). A Harvard PHD 2000 infuse/withdraw apparatus (Harvard Apparatus, Edenbridge, UK) was used to drive cells through the capillary from one barrel to the other either 10, 20 or 30 times. Cells were passed through the capillary at a constant, controlled rate of $50 \mathrm{ml} / \mathrm{min}$. Cells not exposed to capillary shear were used as a control. The capillary entrance and exit zones were tapered to avoid high extensional stress on entry. We assumed the predominant force experienced by cells within the system to be capillary wall shear stress $(\tau)$ and calculated the magnitude of force using the equation derived by Zoro et al. (2009):

$$
\tau \approx 32 Q \mu / \pi d^{3}
$$

where $Q=$ fluid flow rate; $d=$ capillary diameter; $\mu=$ suspension viscosity.

Suspension viscosity of the dilute suspension was assumed to be similar to that of water at $25^{\circ} \mathrm{C}\left(8.9 \times 10^{-4}\right.$ Pa.s) and the flow rate of $50 \mathrm{ml} / \mathrm{min}$ equated to a capillary wall shear stress of $235 \mathrm{~Pa}$.

\section{Cell recovery}

Cell recovery was measured immediately following exposure to shear using the trypan blue exclusion method by mixing cells in suspension with trypan blue dye at a ratio of $1: 1$. Cell counts were preformed using a haemocytometer and non-viable cells were determined on the basis of uptake of dye. 


\section{Cell viability}

Cell viability after $48 \mathrm{~h}$ was determined using MTT dye reduction assay to determine relative amount of viable cells after capillary shearing. Cells that were either capillary-sheared or non-sheared were seeded into 96 well plates at $5 \times 10^{3}$ cells/well (in $\left.100 \mu \mathrm{l}\right)$ and after $48 \mathrm{~h}, 25 \mu \mathrm{l}$ MTT $(5 \mathrm{mg} / \mathrm{ml})$ was added to each well. After $4 \mathrm{hr}$ incubation at $37{ }^{\circ} \mathrm{C}$, medium was removed and $100 \mu \mathrm{l}$ extraction buffer $(20 \% \mathrm{v} / \mathrm{v}$ SDS, $0.5 \mathrm{M}$ dimethyl formamide) was added to each well and cells incubated overnight at $37{ }^{\circ} \mathrm{C}$. Cell viability was determined by reading absorbance at $570 \mathrm{~nm}$ using a Dynex spectrophotometer.

\section{Osteogenic induction of MDPCs after capillary shear}

Capillary-sheared MDPCs were seeded into 24 well plates at $10^{5}$ cells/well. After $24 \mathrm{~h}$, medium was replaced with osteogenic medium consisting of standard culture medium supplemented with $100 \mathrm{nM}$ dexamethasone, 50 $\mu \mathrm{M}$ ascorbate 2-phosphate and $10 \mathrm{mM} \beta$-glycerophosphate. Medium was changed every 3 days.

\section{Myogenic culture conditions}

Capillary-sheared MDPCs were seeded into 24 well plates at $10^{5}$ cells/well. After $24 \mathrm{~h}$, medium was replaced with myogenic medium consisting of DMEM supplemented with 2\% (v/v) FBS and 10 ng IGF-1/ml (SigmaAldrich). Medium was changed every 3 days.

\section{Alizarin Red S quantitation of early mineralization}

Alizarin Red S was used to detect calcified matrix (an early indicator of mineralized matrix deposition). After 2 weeks of culture in either osteogenic or myogenic medium, MDPCs were fixed with $70 \%(\mathrm{v} / \mathrm{v})$ ethanol for $1 \mathrm{~h}$ at $4{ }^{\circ} \mathrm{C}$, then stained with $2 \%(\mathrm{w} / \mathrm{v})$ Alizarin Red S (pH 4.3) in deionised water for $10 \mathrm{~min}$ at room temperature. Photomicrographs were taken on a Nikon Eclipse TE2000-U microscope (Nikon, Kingston-on-Thames, UK). For quantitation, cetylpyridinium chloride $(10 \% \mathrm{w} / \mathrm{v}$ in $10 \mathrm{mM}$ sodium phosphate, $\mathrm{pH} 7.0)$ was used to elute the stain. $100 \mu \mathrm{l}$ aliquots were then transferred to a 96 well plate and absorbance was measured at $570 \mathrm{~nm}$.

\section{Statistical analyses}

All cell culture experiments were carried out in triplicate and analysed using one-way ANOVA followed by Bonferroni correction for multiple testing. Statistical significance was assumed if $\mathrm{p}<0.05$. 


\section{Results and Discussion}

Cells were passed through the capillary at $50 \mathrm{ml} \mathrm{min}^{-1}$, and the first response we assessed was cell viability immediately following capillary flow of duration 10 capillary passes (duration of $12 \mathrm{~s}$ per ml of cell suspension), 20 capillary passes $\left(24 \mathrm{~s} \mathrm{ml}^{-1}\right)$ or 30 capillary passes $\left(36 \mathrm{~s} \mathrm{ml}^{-1}\right)$. For both PP1 and PP3 MDPCs, there was a small but steady decline in viability compared with cells not exposed to shear stress (Figure 1). For PP1 cells, decline in cell viability was statistically significant at 30 capillary passes ( $<<0.05$ vs 0 passes). We also compared cell viability in PP1 and PP3 MDPCs $48 \mathrm{~h}$ after exposure to capillary shear as we previously found that late-adherent cells recovered from the capillary passage regime by $48 \mathrm{~h}$ and were similar to MDPCs that had not been passed through the capillary at this time (Mulhall et al. 2010).

PP1 MDPCs showed a trend of increasing viability up to 20 capillary passes but a substantial drop in viability was noted at 30 passes ( $<0.05$ versus 20 capillary passes; Figure 2$)$. However, the late-adherent PP3 MDPCs all had a similar viability to the non-capillary exposed MDPCs. This data indicates that the capillary flow method we used causes differential effects on cell viability that are consistent between the two MDPC populations over time. In addition, the number of passes and hence duration of exposure to capillary flowinduced shear stress appears to be important, with presumable stimulation of cell number up to 20 capillary passes for PP1 cells; but a significant drop in viability at 30 passes.

Born et al. (1992) reported that capillary wall shear stress of over $100 \mathrm{~N} \mathrm{~m}^{-1}$ was required to cause irreversible damage to suspensions of $\mathrm{TB} / \mathrm{C} 3$ murine hybridomas as a benchmark for the magnitude of forces that mammalian cells in suspension can withstand during bioprocessing. There are some substantial differences in the protocols employed that include duration of capillary flow and phenotypic characteristics of individual cell populations. To elaborate on the latter, the robustness of the individual cell type assessed will vary considerably between different tissues and, as we report here, even within a tissue as the PP3 (late-adherent) cells were less affected by capillary shear stress than PP1 cells in terms of immediate cell viability and later cell recovery/survival.

Cells in different tissues of the body are responsive to physical stimuli which in vivo result from local cell-cell and cell-matrix interactions, along with exposure to forces, such as compressive stress (cartilage and bone), tensile strain (tendons and muscles) and shear stress (blood and endothelia). In vitro, application of forces that mimic the in vivo environment can promote cell responses and numerous studies have demonstrated that 
enhanced osteogenic induction of bone marrow-derived stromal cells can be achieved using laminar flow in both monolayer (Grellier et al. 2009; Kreke et al. 2008) and in 3D bioreactors (Bancroft et al. 2002; Gomes et al. 2003; Stiehler et al. 2009). We have previously demonstrated that passing late-adherent MDPCs through a narrow-gauge capillary can enhance osteogenic differentiation even though the cells are of a muscle origin (Mulhall et al. 2010). This has obvious implications for bioprocessing of cell material for therapeutic purposes as it indicates that forces that might be encountered during large-scale, automated expansion of progenitor cell populations might promote differentiation events that could be undesirable (particularly if osteogenic cells are not the desired target cells of the process).

In this study we compared the osteogenic differentiation potential of early-adherent PP1 and late-adherent PP3 MDPCs. Cells were exposed to capillary flow, plated and then cultured in either osteogenic or myogenic medium for two weeks. PP1 MDPCs cultured in osteogenic medium produced $>3$ fold increase in Alizarin Red S staining which indicates early events in mineralization of extracellular matrix that typifies osteogenic differentiation, compared with cells cultured in standard culture medium (Figure 3A and Table 1). PP3 MDPCs cultured in osteogenic medium only underwent a $>2$-fold increase compared with normal growth medium (Figure 3B), reflecting their greater commitment to the myogenic lineage and reduced capacity to undergo osteogenic differentiation. Capillary wall shear stress produced an additive effect to the osteogenic medium by inducing a small but significant increase in osteogenic induction after 30 capillary shear passes compared with unsheared cells $(\mathrm{p}<0.01$; Figure $3 \mathrm{~A})$. This also occurred in the instance of PP3 MDPCs $(\mathrm{p}<0.01$; Figure 3B). Even when cultured in myogenic medium, the intrinsically more myogenic PP3 MDPCs exposed to capillary flow exhibited small but significant increases in Alizarin Red S staining (Figure 3D), indicating that the kind of forces experienced in the bioprocessing environment might induce a degree of heterotopic differentiation that will potentially compromise the therapeutic cell population. Generally though, capillary-sheared PP3 MDPCs cultured in myogenic medium produced only 0.4-fold Alizarin Red staining compared with cells grown in standard growth medium, whereas the intrinsically more multipotent PP1 produced elevated levels of 0.7 -fold staining in myogenic medium compared to standard growth medium (Figure 3C-D). Exposing PP1 cells cultured in myogenic medium to capillary wall shear stress did not induce significant changes in Alizarin Red S staining ( $>0.1$; Figure 3C) whereas PP3 cells produced small but significant increases in staining after 20 and 30 capillary passes $(\mathrm{p}<0.05$; Figure $3 \mathrm{D})$. 
This study differs from previous studies of shear stress and osteogenic differentiation as we characterized the effects of capillary flow, one aspect of the whole bioprocess that cells are exposed to during preparation for therapy, rather than the effect of laminar flow on cells that are already adhered to a substrate. We considered the effect of capillary flow in terms of wall shear stress, which based on previous studies, is assumed to be the highest magnitude force in the system (Zoro et al. 2009). Furthermore, we assessed the differential effects on different subsets of cells that were separated on the basis of differential adherence. Consequently we have demonstrated that a capillary wall shear stress of $235 \mathrm{~N} \mathrm{~m}^{-2}$ can be applied subsets of MDPCs and that these cells have differential capacities to withstand the effects of capillary shear stress. The capacity for MDPCs (derived from skeletal muscle) to withstand shear stress is somewhat greater than that of aortic smooth muscle cells tested in previous studies (Zoro et al. 2008). For large-scale manufacturing of regenerative cell therapies, something that will become an integral part of the bioprocessing industry over the next few decades, it will be important to understand how bioprocessing forces can influence behaviour of the therapeutic cells being produced.

\section{References}

Bancroft GN, Sikavitsas VI, van den Dolder J, Sheffield TL, Ambrose CG, Jansen JA, Mikos AG (2002) Fluid flow increases mineralized matrix deposition in 3D perfusion culture of marrow stromal osteoblasts in a dose-dependent manner. Proc Natl Acad Sci U S A 99 (20):12600-12605.

Born C, Zhang Z, Al-Rubeai M, Thomas CR (1992) Estimation of disruption of animal cells by laminar shear stress. Biotechnol Bioeng 40 (9):1004-1010.

Davies LC, Locke M, Webb RD, Roberts JT, Langley M, Thomas DW, Archer CW, Stephens P (2010) A Multipotent Neural Crest Derived Progenitor Cell Population is Resident within the Oral Mucosa Lamina Propria. Stem Cells Dev.

Dowthwaite GP, Bishop JC, Redman SN, Khan IM, Rooney P, Evans DJ, Haughton L, Bayram Z, Boyer S, Thomson B, Wolfe MS, Archer CW (2004) The surface of articular cartilage contains a progenitor cell population. J Cell Sci 117 (Pt 6):889-897.

Gomes ME, Sikavitsas VI, Behravesh E, Reis RL, Mikos AG (2003) Effect of flow perfusion on the osteogenic differentiation of bone marrow stromal cells cultured on starch-based three-dimensional scaffolds. J Biomed Mater Res A 67 (1):87-95.

Grellier M, Bareille R, Bourget C, Amedee J (2009) Responsiveness of human bone marrow stromal cells to shear stress. J Tissue Eng Regen Med 3 (4):302-309. 
Jones PH, Watt FM (1993) Separation of human epidermal stem cells from transit amplifying cells on the basis of differences in integrin function and expression. Cell 73 (4):713-724.

Knippenberg M, Helder MN, Doulabi BZ, Semeins CM, Wuisman PI, Klein-Nulend J (2005) Adipose tissuederived mesenchymal stem cells acquire bone cell-like responsiveness to fluid shear stress on osteogenic stimulation. Tissue Eng 11 (11-12):1780-1788.

Kreke MR, Sharp LA, Lee YW, Goldstein AS (2008) Effect of intermittent shear stress on mechanotransductive signaling and osteoblastic differentiation of bone marrow stromal cells. Tissue Eng Part A 14 (4):529537.

Lee JY, Qu-Petersen Z, Cao B, Kimura S, Jankowski R, Cummins J, Usas A, Gates C, Robbins P, Wernig A, Huard J (2000) Clonal isolation of muscle-derived cells capable of enhancing muscle regeneration and bone healing. J Cell Biol 150 (5):1085-1100

Mulhall H, Patel M, Al-Qathani K, Mason C, Lewis MP, Wall I (2010) Effect of capillary shear stress on recovery and osteogenic differentiation of muscle-derived precursor cell populations. Journal of Tissue Engineering and Regenerative Medicine in press

Rando TA, Blau HM (1994) Primary mouse myoblast purification, characterization, and transplantation for cellmediated gene therapy. J Cell Biol 125 (6):1275-1287

Sinanan AC, Buxton PG, Lewis MP (2006) Muscling in on stem cells. Biol Cell 98 (4):203-214.

Stiehler M, Bunger C, Baatrup A, Lind M, Kassem M, Mygind T (2009) Effect of dynamic 3-D culture on proliferation, distribution, and osteogenic differentiation of human mesenchymal stem cells. J Biomed Mater Res A 89 (1):96-107.

Veraitch FS, Scott R, Wong JW, Lye GJ, Mason C (2008) The impact of manual processing on the expansion and directed differentiation of embryonic stem cells. Biotechnol Bioeng 99 (5):1216-1229.

Zoro BJ, Owen S, Drake RA, Hoare M (2008) The impact of process stress on suspended anchorage-dependent mammalian cells as an indicator of likely challenges for regenerative medicines. Biotechnol Bioeng 99 (2):468-474.

Zoro BJ, Owen S, Drake RA, Mason C, Hoare M (2009) Regenerative medicine bioprocessing: concentration and behavior of adherent cell suspensions and pastes. Biotechnol Bioeng 103 (6):1236-1247. 
Figure legends

Figure 1: Recovery of MDPCs immediately following exposure to capillary wall shear stress. Early-adherent PP1 cells underwent a gradual decline in recovery with increasing duration of capillary shear. The same conditions did not affect recovery of late-adherent cells. $\mathrm{N}=$ number of viable cells after treatment; $\mathrm{N}_{0}=$ number of viable cells in unsheared cell samples; ${ }^{*} \mathrm{p}<0.05$ versus 0 passes.

Figure 2: Viability of MDPCs was assessed in adherent populations of cells $48 \mathrm{~h}$ after exposure to capillary shear stress using the MTT assay. Early-adherent PP1 underwent a gradual increase in cell number compared to nontreated cells after up to 20 capillary passes, but then a significant reduction was observed after 30 capillary passes. For PP3 cells, no significant variation in cell viability was evident. $\mathrm{N}=$ number of viable cells after treatment; $\mathrm{N}_{0}=$ number of viable cells in unsheared cell samples; ${ }^{*} \mathrm{p}<0.05$ versus 20 passes.

Figure 3: Osteogenic capacity of MDPCs after 2 weeks in culture, measured as a function of Alizarin Red S staining intensity. PP1 cells produced $>3$-fold increase in Alizarin Red S stain compared to cells grown in normal medium (A). PP3 cultured in osteogenic medium underwent less osteogenic induction (producing $>2$ fold increase in staining) compared to normal growth medium control (B). Both PP1 (C) and PP3 (D) MDPCs cultured in myogenic medium underwent reduced Alizarin Red S staining compared even to normal medium controls (0.7-fold and 0.4-fold respectively). For A, B and D, exposure of MDPCs to capillary shear stress promoted additive osteogenic effects. ${ }^{*} \mathrm{p}<0.05$, $* * \mathrm{p}<0.01$, both versus 0 passes. 
Table1I: Fold-change in Alizarin Red S staining intensity versus non-capillary-sheared cells cultured in normal growth medium

\begin{tabular}{ccccc} 
Capillary & \multicolumn{2}{c}{ Osteogenic medium } & \multicolumn{2}{c}{ Myogenic medium } \\
\cline { 2 - 5 } passes & PP1 & PP3 & PP1 & PP3 \\
\hline $\mathbf{0}$ & 3.29 & 2.1 & 0.71 & 0.42 \\
$\mathbf{1 0}$ & 3.23 & 2.31 & 0.71 & 0.37 \\
$\mathbf{2 0}$ & 3.48 & 2.36 & 0.76 & 0.46 \\
$\mathbf{3 0}$ & 3.72 & 2.40 & 0.72 & 0.47
\end{tabular}

